\title{
Release of insulin produced by the choroid plexis is regulated by serotonergic signaling
}

\author{
Caio Henrique Mazucanti, Qing-Rong Liu, Doyle Lang, Nicholas Huang, Jennifer F. O'Connell, \\ Simonetta Camandola, and Josephine M. Egan
}

National Institute on Aging, Intramural Research Program, Baltimore, Maryland, USA.

\begin{abstract}
The choroid plexus (ChP) is a highly vascularized tissue found in the brain ventricles, with an apical epithelial cell layer surrounding fenestrated capillaries. It is responsible for the production of most of the cerebrospinal fluid (CSF) in the ventricular system, subarachnoid space, and central canal of the spinal cord, while also constituting the blood-CSF barrier (BCSFB). In addition, epithelial cells of the ChP (EChP) synthesize neurotrophic factors and other signaling molecules that are released into the CSF. Here, we show that insulin is produced in EChP of mice and humans, and its expression and release are regulated by serotonin. Insulin mRNA and immune-reactive protein, including C-peptide, are present in EChP, as detected by several experimental approaches, and appear in much higher levels than any other brain region. Moreover, insulin is produced in primary cultured mouse EChP, and its release, albeit $\mathrm{Ca}^{2+}$ sensitive, is not regulated by glucose. Instead, activation of the $5 \mathrm{HT} 2 \mathrm{C}$ receptor by serotonin treatment led to activation of IP3-sensitive channels and $\mathrm{Ca}^{2+}$ mobilization from intracellular storage, leading to insulin secretion. In vivo depletion of brain serotonin in the dorsal raphe nucleus negatively affected insulin expression in the ChP, suggesting an endogenous modulation of $\mathrm{ChP}$ insulin by serotonin. Here, we show for the first time to our knowledge that insulin is produced by EChP in the brain, and its release is modulated at least by serotonin but not glucose.
\end{abstract}

Conflict of interest: The authors have declared that no conflict of interest exists.

Copyright: (c) 2019, American Society for Clinical Investigation.

Submitted: July 10, 2019

Accepted: October 16, 2019

Published: December 5, 2019.

Reference information: /CI Insight.

2019;4(23):e131682.

https://doi.org/10.1172/jici.

insight.131682.

\section{Introduction}

Exploring the roles of insulin and its downstream signaling in the brain is an ongoing area of research because of its reported involvement in brain function in aging and disease. There is substantial epidemiological data supporting a role for insulin resistance in Alzheimer's disease and reduced life span in humans (1-5). However, there are also substantial data for reduced insulin and IGF1 signaling in preventing neurodegeneration in mice $(6,7)$ and in extending life spans in worms, flies, mice and maybe even in higher-order mammals (8-12). These data clearly seem in direct conflict since, in both cases, there is reduced downstream insulin signaling. However, it is entirely possible, as already suggested (13), that there are differences in total organismal metabolic outcome between insulin resistance in insulin-sensitive tissues (e.g., liver, fat, and muscle) that are reliant on insulin for glucose uptake, and decreased insulin signaling in so-called insulin-insensitive cells, such as neurons, as it could occur due to reductions in the availability of the insulin molecule itself within the brain. It is also possible to have both scenarios present in the same organism. Indeed, intranasal insulin is now being investigated in humans as a way to increase the availability of insulin to brain areas and study its impact on cognition and amyloid $\beta(\mathrm{A} \beta)$ plaque deposition in humans with insulin resistance (14). For all these reasons, it seems important to clarify the source of insulin in the brain.

Insulin in circulation may be transported into the brain by a putative transporter $(15,16)$, but whether it is actually produced in the brain of higher-order organisms is unsettled. In C. elegans, insulin-like peptides are produced by sensory neurons (17), and in Drosophila, they are expressed exclusively in the brain (18). In chordates, insulin mRNA is found in the nervous system of tunicates (19), as well as in the brain and pituitary gland of fish (20). In mammals, insulin and C-peptide are produced in taste cells within taste buds of the lingual epithelium (21), and taste cells contain the proconvertases necessary for mature insulin production (22). The presence of immunoreactive insulin has also been reported in sustentacular cells of the olfactory epithelium (23). Work carried out in the late 1970s first raised the possibility that insulin is produced in 
different regions of the rat brain $(24,25)$, and today, there is a growing number of reports describing insulin expression in some brain regions, such as hippocampus and hypothalamus, in rodents (26-28). Therefore, there is clear precedent for extrapancreatic insulin production in a location far removed from the pancreas.

Insulin production in the brain, however, is a controversial topic. Conflicting data about insulin production in brain structures and cell types are abundant. Indications that neurons are capable of producing and secreting insulin were first reported in 1986 in a whole-brain primary neuronal culture but not in primary glial culture (29). Insulin mRNA and protein were reported in pyramidal cells in the hippocampus and in the olfactory bulb (30), whereas a broader insulin expression in the brain - encompassing hippocampus, striatum, hypothalamus, entorhinal, and prefrontal cortices and low levels in olfactory bulbs - was later described (31). More recently, insulin secretion was also reported in cultured astrocytes (32), adding to the controversy.

In order to identify possible sites of insulin production in the brain, we first carried out fluorescent in situ hybridization (FISH) for insulin expression across slices of whole mouse brain. The one structure that gave a clear, unequivocal signal over multiple brain sections was the choroid plexus (ChP); all other brain areas gave either a weak signal, by comparison with ChP, or no signal. We therefore concentrated further attention on this structure. Here, we describe the presence not only of insulin mRNA, but also of the protein itself in the epithelial layer of the $\mathrm{ChP}$ of mice and humans, along with proteins associated with insulin processing and secretion, using a range of diverse investigational methods. Insulin and C-peptide are also clearly present in cultured primary epithelial cells of the $\mathrm{ChP}(\mathrm{EChP})$. We compared insulin expression and related proteins across the $\mathrm{ChP}$ of the lateral and fourth ventricles (LV and 4thV, respectively), and we further investigated the modulation of insulin expression and the underlying molecular mechanisms and intracellular pathways necessary for its secretion using in vitro and in vivo approaches.

\section{Results}

ChP expresses and produces insulin but not islet amyloid polypeptide. Rodents such as mice and rats have 2 insulin genes: Ins1 expression is thought to be restricted to pancreatic $\beta$ cells in islets of Langerhans, whereas Ins2, the ancestral gene, possibly has a broader tissue expression pattern. We have previously reported that Ins 2 is expressed and mature insulin is synthesized in taste cells within taste buds (21). FISH for Ins2 RNA in brain sections reveals a clear, strong signal only in the $\mathrm{ChP}$ (Figure 1A) and colocalized with ChP marker transthyretin (Ttr), while Ins1 was detected at low levels (Figure 1B). Insulin is transcribed as a preproprotein, a single polypeptide composed of a signal peptide, $\beta$ chain, C-peptide, and $\alpha$ chain. The signal peptide is needed for translocation to and across the endoplasmic reticulum (ER), where it is cleaved from the preproinsulin molecule. Proinsulin exits the ER and is delivered to the Golgi apparatus for packaging in secretory vesicles. With the maturation and acidification of these vesicles, proinsulin is cleaved by proconvertases, freeing the C-peptide (33). Insulin staining in $\mathrm{ChP}$ from perfused animals shows a pattern congruent with insulin secretion into the CSF (Figure 1C); the apical layer of the $\mathrm{ChP}$ is stained positive, while the stroma, which is highly vascularized, is absent of signal. C-peptide immunofluorescence (IF) signal is also present in the $\mathrm{ChP}$, an additional confirmation that insulin is being produced locally (Figure 1C). IHC of human ChP sections for insulin and C-peptide are also consistent with this finding (Figure 1, D and E). C-peptide clearly has a perinuclear and apical signal (Figure 1E) within ChP, and IHC of insulin has an apical staining (Figure 1D). Specificity of our detection methods are shown in Supplemental Figure 1 (supplemental material available online with this article; https://doi.org/10.1172/jci.insight.131682DS1).

Compared with islets isolated from mouse pancreata, the profile of Ins 2 expression in the ChP is vastly different. The Ins2 gene has 3 known splicing variants (ref. 34 and Figure 2A), and quantitative PCR (qPCR) analysis for each specific variant reveals differential isoform expression patterns between the $\mathrm{ChP}$ and islets. The transcript variant 2 of the Ins2 RNA (hereafter referred as Ins2-2) is the main splicing variant found in islets, while it has low expression in the ChP (Figure 2B). On the other hand, variants 1 and 3 (Ins2-1 and Ins2-3, respectively) are the major isoforms expressed in the $\mathrm{ChP}$, while their relative levels in the islets are approximately 50 times lower than Ins2-2 (Figure 2B). Expanding the comparison of Ins2 expression to other brain regions, we find that Ins 2 mRNA variants have higher levels of expression in the $\mathrm{ChP}$ than in any other brain area, with the exception of the olfactory bulb, in which Ins2-2 and Ins2-3 expression levels are similar with ChP (Figure 2, C-E). All results are summarized in Table 1.

The ChP of the lateral and third ventricles develop independently from that of the 4thV; however, the ventricles are connected through the aqueduct of Sylvius, which does not contain ChP. In attempting to further characterize insulin expression in the ChP, we compared the expression levels of Ins 1 and Ins 2 between 

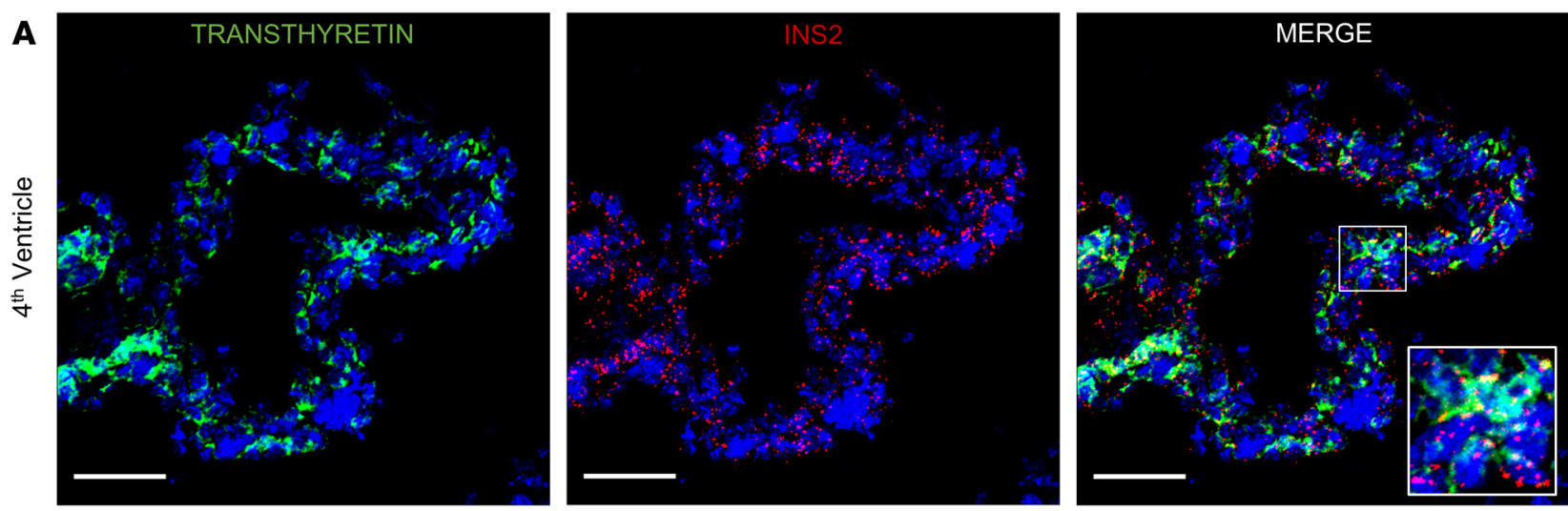

B

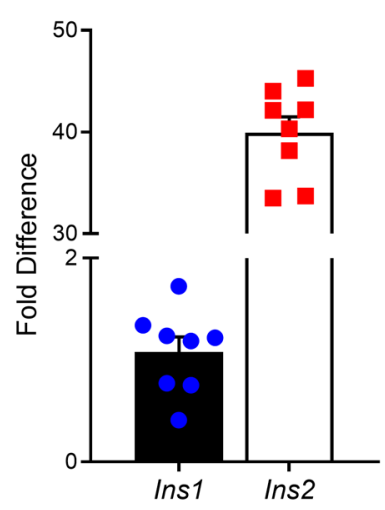

C
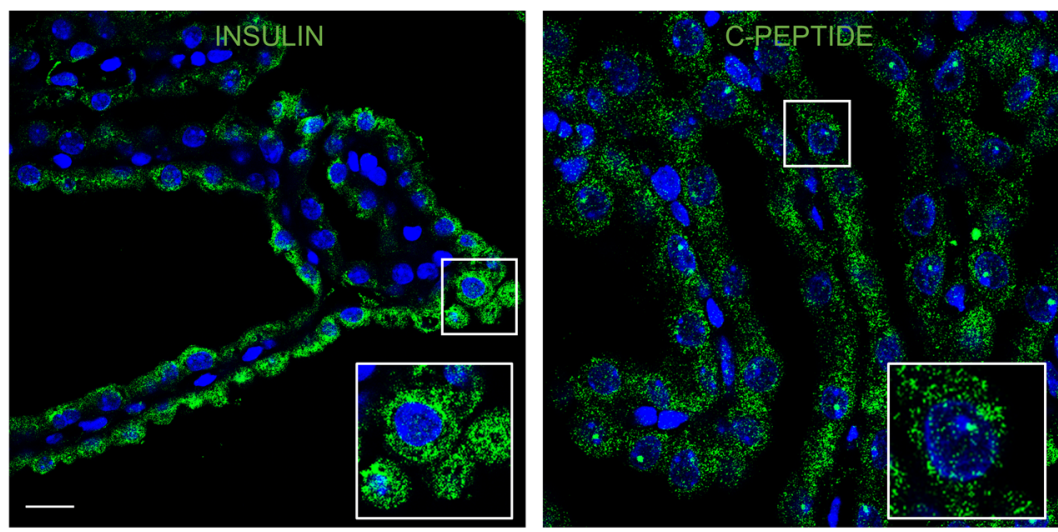

D

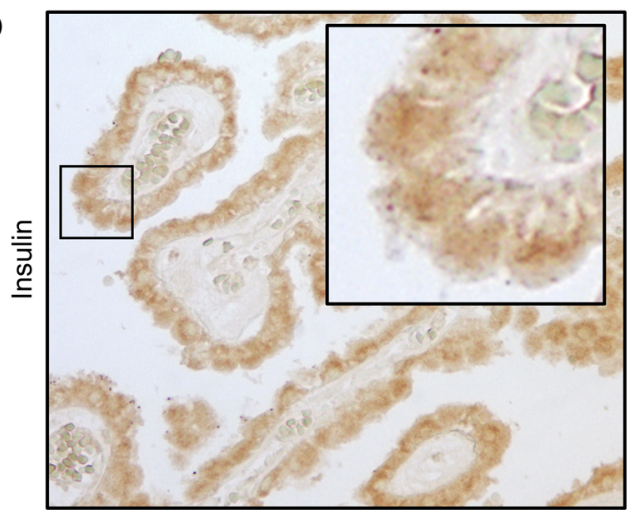

$\mathbf{E}$

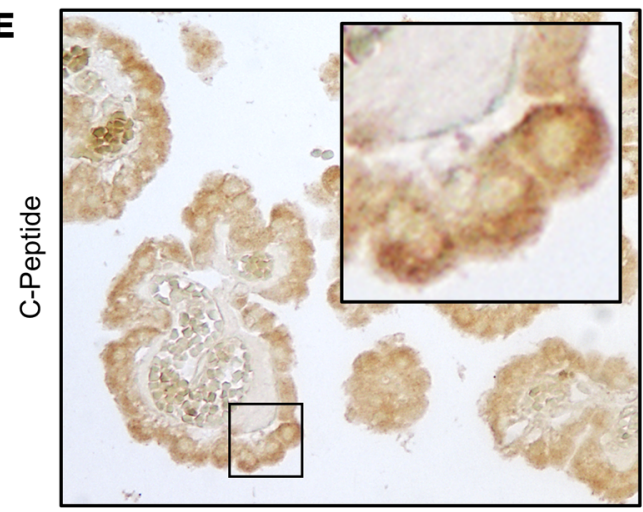

Figure 1. Insulin is expressed and produced in the choroid plexus. (A) Fluorescent in situ hybridization of sagittal sections of mouse brain for Ins2 (red) and transthyretin (green) RNA reveals strong coexpression of the insulin gene in epithelial cells of the choroid plexus. Scale bar: $50 \mu \mathrm{m}$. (B) In rodents, insulin is coded by 2 different genes. Relative qPCR data comparing Ins1 and Ins2 expression levels confirm predominant Ins2 expression in the tissue. (C) Immunoreactive insulin and C-peptide are detectable in the epithelial layer of the choroid plexus. Scale bar: $20 \mu \mathrm{m}$. (D and $\mathbf{E}$ ) In the human choroid plexus, insulin and C-peptide are also detectable, where they localize at perinuclear and apical regions of the cells.

the $\mathrm{ChP}$ of the fore (lateral ventricles) and hindbrain (4thV) (Figure 2F). Interestingly, expression levels of Ins 1, Ins2-1, and Ins2-3 are consistently higher in the hindbrain ChP. We also investigated the expression of the enzymes necessary for the conversion of preproinsulin (the translated product of the insulin gene) into the active mature insulin. The genes of both proconvertases 1/3 (Pcsk1) and 2 (Pcsk2) are expressed in the ChPs, with higher levels of Pcsk2 expression in the 4thV ChP (Figure 2F). We could not detect islet amyloid polypeptide (IAPP), which is stored and coreleased with insulin in pancreatic $\beta$ cells, by FISH, PCR, or immunostaining in either $\mathrm{ChP}$ or primary EChP (data not shown).

Once translated and processed in pancreatic $\beta$ cells, insulin is stored in vesicles that dock to the cell membrane through a $\mathrm{Ca}^{2+}$-sensitive soluble N-ethylmaleimide-sensitive factor (NSF) attachment protein receptor (SNARE) complex (Figure 3A). Western blotting analysis of protein extracted from choroid plexi 
A

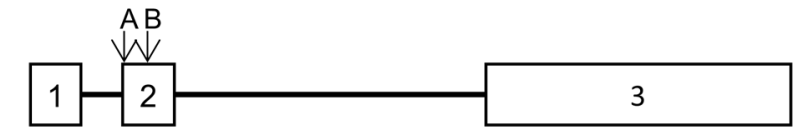

Mouse Ins2 transcript variants

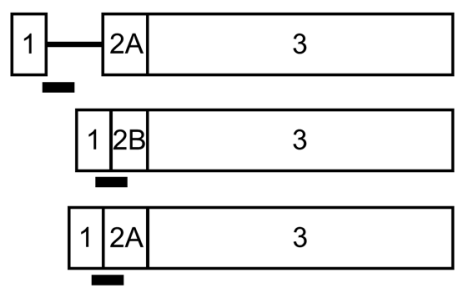

Ins 2-1: NM_001185084.2

Ins 2-2: NM_001185083.2

Ins 2-3: NM 008387.5
B

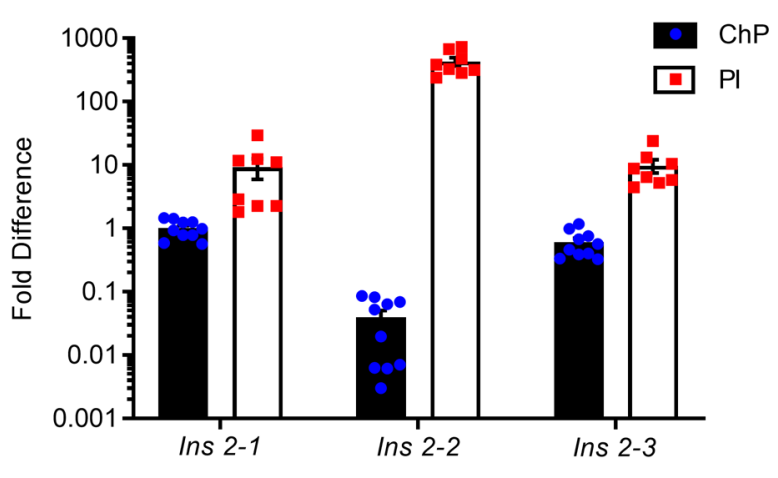

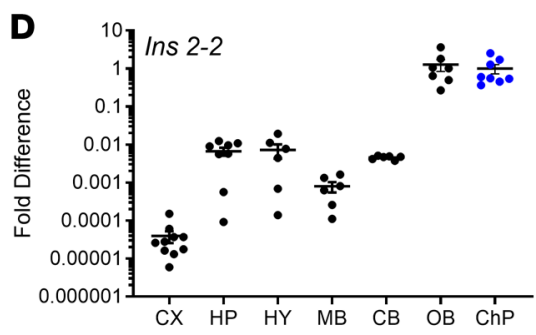

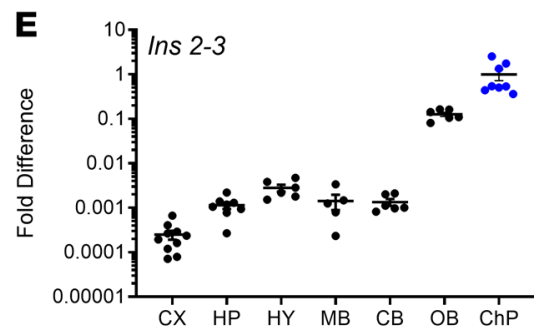

$\mathbf{F}$

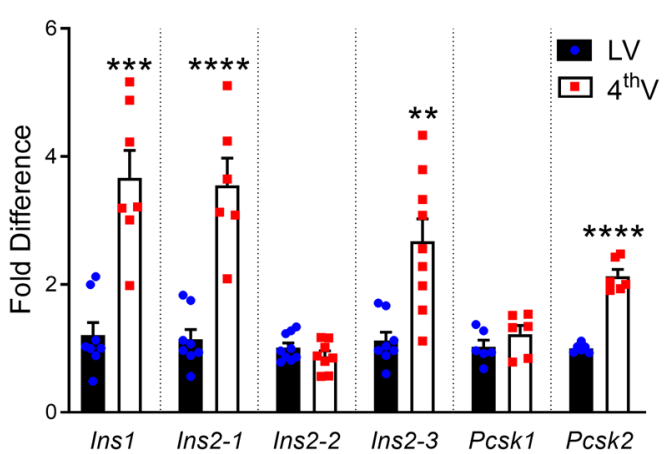

Figure 2. Insulin transcript variants and proconvertase RNA are differentially expressed throughout the brain. (A) Mouse Ins2 gene has 3 transcript variants. (B) Specific insulin transcripts are differentially expressed in the choroid plexus and pancreatic islets. Values are compared with ChP Ins2-1 expression, and results are summarized in Table 1. (C-E) In the brain, all 3 transcript variants are more abundantly expressed in the choroid plexus than any other brain structure. Results are summarized in Table 1. (F) Comparison of insulin expression levels in telencephalic and hindbrain choroid plexus present in the lateral and fourth ventricle, respectively (as depicted in the schematic diagram), reveals higher levels in the posterior ChP, a trend also observed for 2 important enzymes necessary for proinsulin maturation (Ins1: LV ChP mean $=1.206$, SEM $=0.1987,4$ thV ChP mean $=3.668, \mathrm{SEM}=0.4292, n=7-8$; Ins2-1: LV ChP mean $=1.141$, SEM $=0.1536,4$ thV ChP mean $=3.550, \mathrm{SEM}=0.4261, n=6-8 ;$ Ins2-3: LV ChP mean = 1.120, SEM = 0.1348, 4thV ChP mean $=2.674, \mathrm{SEM}=0.3501, n=8-9 ; P c s k 2:$ LV ChP mean $=1.002, \mathrm{SEM}=0.02841,4$ thV ChP mean $=2.131, \mathrm{SEM}=0.1031, n=6)$. Student's $t$ test, ${ }^{* *} P<0.01 ;{ }^{* * *} P<0.001 ;{ }^{* * *} P<0.0001$. CB, cerebellum; ChP, choroid plexus; CX, cortex; HP, hippocampus; HY, hypothalamus; MB, midbrain; OB, olfactory bulb; PI, pancreatic islets.

revealed the presence of vesicle-associated proteins necessary for $\mathrm{Ca}^{2+}$-dependent vesicular extrusion (Figure 3, A and B). SNARE complex proteins necessary for insulin secretion in $\beta$ cells (35) are also present in the ChP, such as the target SNAREs (t-SNAREs) syntaxin-1a (STX1A) and synaptosomal nerve-associated protein 25 (SNAP25), the vesicular SNARE (v-SNARE) vesicle-associated membrane protein 2 (VAMP2), and the arginine SNARE (R-SNARE) NSF, as well as synaptotagmin-1 (SYT1) (Figure 3; see complete unedited blots in the supplemental material). STX1A, VAMP2, NSF, SNAP25, and SYT1 were present at higher levels in the $\mathrm{ChP}$ of the $4 \mathrm{thV}$ compared with the $\mathrm{ChP}$ from the lateral ventricle, reinforcing our observation that the hindbrain ChP expresses higher levels of insulin.

Serotonin, but not glucose, induces intracellular $\mathrm{Ca}^{2+}$ oscillation in $\mathrm{EChP}$. We used primary cultured $\mathrm{EChP}$ to further investigate the mechanisms of regulated insulin secretion. As confirmed in Figure 4A, immunoreactive insulin and $\mathrm{C}$-peptide are detectable in cultured $\mathrm{EChP}$, which are characterized by the expression of ZO-1, a protein necessary for tight junction formation. The presence of $\mathrm{Ca}^{2+}$-sensitive proteins associated 
Table 1. Differential expression of specific splicing variants of the insulin gene

\begin{tabular}{|c|c|c|c|c|c|c|c|c|c|}
\hline & \multicolumn{3}{|c|}{ Ins2-1 } & \multicolumn{3}{|c|}{ Ins2-2 } & \multicolumn{3}{|c|}{ Ins2-3 } \\
\hline & Mean & SEM & $n$ & Mean & SEM & $n$ & Mean & SEM & $n$ \\
\hline ChP & 1.00 & 0.2646 & 8 & 1.00 & 0.2728 & 8 & 1.00 & 0.2802 & 8 \\
\hline HP & $8.96 \mathrm{E}-05$ & $1.57 \mathrm{E}-05$ & 8 & $6.70 \mathrm{E}-03$ & $1.61 \mathrm{E}-03$ & 8 & 1.14E-03 & $1.95 \mathrm{E}-04$ & 8 \\
\hline HY & $6.83 \mathrm{E}-04$ & $5.30 \mathrm{E}-04$ & 5 & $7.22 \mathrm{E}-03$ & $2.95 \mathrm{E}-03$ & 6 & $2.80 \mathrm{E}-03$ & $5.04 \mathrm{E}-04$ & 6 \\
\hline MD & 8.00E-04 & $3.20 \mathrm{E}-04$ & 6 & 7.90E-04 & $2.40 \mathrm{E}-04$ & 6 & $1.42 \mathrm{E}-03$ & $5.30 \mathrm{E}-04$ & 5 \\
\hline
\end{tabular}

CB, cerebellum; ChP, choroid plexus; CX, cortex; HP, hippocampus; HY, hypothalamus; MD, midbrain; OB, olfactory bulb.

with secretory vesicle fusion in protein homogenate of the $\mathrm{ChP}$ led us to investigate signals that are able to produce intracellular $\mathrm{Ca}^{2+}\left(\mathrm{iCa}^{2+}\right)$ increase in $\mathrm{EChP}$ cultured cells. In pancreatic $\beta$ cells, glucose is known to induce cell depolarization by inhibiting ATP-sensitive potassium channels, which ultimately results in $\mathrm{Ca}^{2+}$ influx through voltage-gated $\mathrm{Ca}^{2+}$ channels. In order to check if a similar phenomenon happens in the $\mathrm{ChP}$, EChP were maintained in culture medium with low glucose $(1 \mathrm{mM})$ overnight and then loaded with the $\mathrm{Ca}^{2+}$ fluorescent probe Fluo-8. $\mathrm{Ca}^{2+}$ oscillations during live cell imaging following glucose stimulation ( $25 \mathrm{mM}$ final concentration) were no different from our osmolarity control (mannitol) (Figure 4B). An increase in intracellular cAMP levels by acute forskolin treatment also did not change cytosolic $\mathrm{Ca}^{2+}$ (data not shown). Similarly, a GLP1 receptor agonist, exendin-4, had no effect on $\mathrm{iCa}^{2+}$ concentrations (Supplemental Figure 2A).

Because the $\mathrm{ChP}$ has a high density of serotonin receptors (36), we investigated the EChP response to serotonin. At a final concentration of $5 \mu \mathrm{M}$, serotonin induced an acute, 3-fold increase in the fluorescence intensity (Figure 4, C and D) emitted by the $\mathrm{Ca}^{2+}$ probe. $\mathrm{Ca}^{2+}$ mobilization from intracellular storages was confirmed using a $\mathrm{Ca}^{2+}$-free medium containing EGTA (Figure 4D). Comparison of AUC between the 2 groups showed no statistical difference, suggesting that the entirety of the $\mathrm{iCa}^{2+}$ increase elicited by serotonin comes from $\mathrm{iCa}^{2+}$ storage sites (Figure 4D).

Involvement of IP3 receptors (IP3R) in this serotonin-dependent $\mathrm{Ca}^{2+}$ increase was assessed using the IP3R blocker $2 \mathrm{APB}$ at a final concentration of $150 \mu \mathrm{M}$. Under such conditions, serotonin completely failed to elicit any $\mathrm{iCa}^{2+}$ increase (Figure $4 \mathrm{E}$ ). Similarly, no $\mathrm{Ca}^{2+}$ mobilization was seen when the serotonin receptor HTR2C, a $\mathrm{G}_{\mathrm{q} / 11}$-coupled metabotropic receptor, was antagonized with RS102221 (50 $\left.\mu \mathrm{M}\right)$ when cells were stimulated with serotonin (Figure 4E). We also looked for the possible involvement of ryanodine receptors (RYRs) in this phenomenon by blocking RYRs with dantrolene (10 $\mu \mathrm{M})$, and we concluded that they do not play any role in the calcium mobilization induced by serotonin (Supplemental Figure 2A).

Insulin produced in the ChP is actively secreted. We treated primary EChP for 24 hours with serotonin (5 $\mu \mathrm{M})$ and/or IP3R antagonist 2APB $(150 \mu \mathrm{M})$ and determined insulin concentration in the supernatant using an ultrasensitive ELISA. Supernatant from untreated cultures had a mean insulin concentration of $0.025 \mu \mathrm{g} / \mathrm{L}$, and serotonin treatment induced a statistically significant $42 \%$ increase in insulin concentration (Figure 5A), which was completely prevented by 2APB cotreatment. Interestingly, 2APB treatment by itself led to a $35 \%$ reduction in insulin levels in the supernatant, further suggesting a role for IP3Rs in insulin secretion in these cells (Figure 5A). In addition to insulin-secretion stimulation, EChP treated with serotonin also exhibited higher levels of Ins 1 and Ins 2 mRNA after 4 hours of stimulus, as evaluated by qPCR (Figure 5B). Protein content, as evaluated by Western blotting, of cells treated with serotonin also had higher levels of vesicular proteins associated with insulin secretion in $\beta$ cells (Figure 5C; see complete unedited blots in the supplemental material). Even though acute (4 hours) treatment with exendin-4 (10 $\mathrm{nM}$ ) did not have any effect on insulin secretion (Supplemental Figure 2B), it had a positive effect on Ins2 expression levels (Supplemental Figure 2C).

With a polarized structure, the EChP display different apical (CSF-facing) and basal (blood vessel-facing) membranes. In order to further understand the interplay between serotonin and $\mathrm{ChP}$ insulin secretion, permeable membrane support inserts were used as substrate for primary EChP. Once confluent, these cells form tight junctions, as shown by ZO-1 staining (Figure 5E), effectively isolating 2 compartments in the cell culture system. Complete confluency was confirmed using a voltohmmeter to assess 

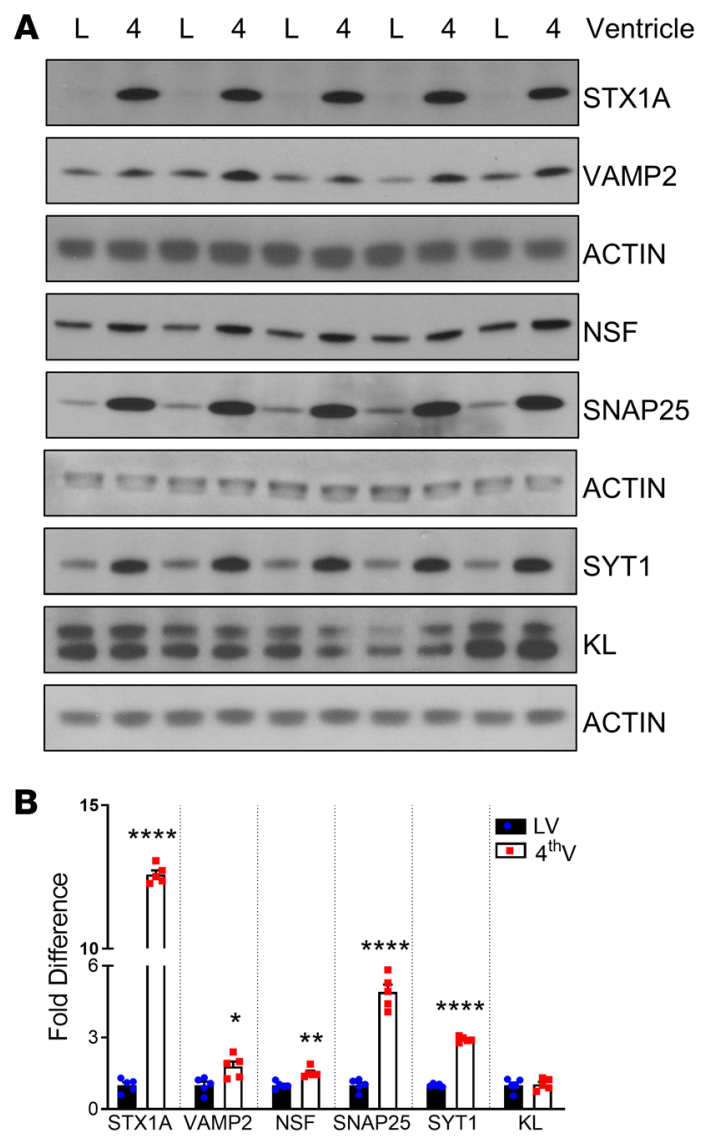

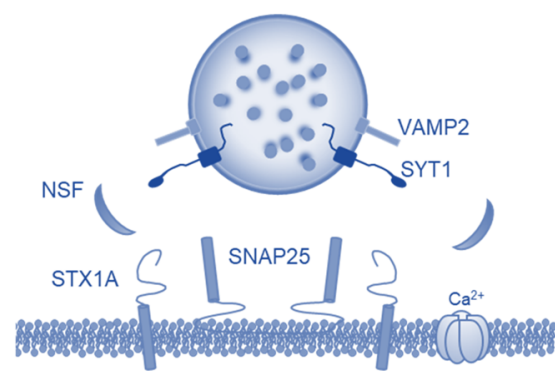

Figure 3. Vesicle docking proteins necessary for $\mathrm{Ca}^{2+}$-dependent insulin secretion in $\beta$ cells are found in the choroid plexus. (A) In $\beta$ cells, insulin is stored in secretory granules that are anchored to the cell membrane by a $\mathrm{Ca}^{2+}$-sensitive SNARE complex. Western blotting analysis of protein homogenates from lateral ventricle and fourth ventricle (4thV) choroid plexi revealed presence of several proteins associated with secretory vesicle docking and $\mathrm{Ca}^{2+}$-dependent exocytosis, suggesting vesicular storage and signal-induced release of insulin in epithelial cells of the choroid plexus. (B) Comparison of relative protein levels between the lateral and 4 thV choroid plexus indicate a more abundant presence of secretory vesicles in the hindbrain choroid plexus (VAMP2: LV ChP mean $=1.0, \mathrm{SEM}=0.1488,4$ thV ChP mean $=1.786, \mathrm{SEM}=0.2110, n$ $=5, P=0.0159$; NSF: LV ChP mean $=1.0, \mathrm{SEM}=0.06718,4 \mathrm{thV} \mathrm{ChP}$ mean $=1.524, \mathrm{SEM}=0.09163, n=5$, $P=0.017$; SNAP25: LV ChP mean $=$ 1.0, SEM $=0.1123,4$ thV ChP mean $=4.905, \mathrm{SEM}=0.3105, n=5, P<$ 0.0001; SYT1: LV ChP mean $=1.0$ $\mathrm{SEM}=0.02911,4^{\text {th }} V$ ChP mean $=$ 2.920, SEM $=0.05070, n=5, P<$ $0.0001)$. Student's $t$ test, ${ }^{*} P<0.05$; ${ }^{* *} P<0.01 ;{ }^{* * *} P<0.0001$

the transepithelial electrical resistance (TEER) between the 2 compartments, and readings between 100 $150 \Omega \mathrm{cm}^{2}$ were considered compatible with confluent cultures. In this system, the apical membrane of the cells faces the upper compartment, while the basal membrane faces the permeable layer of the support (Figure 5D). Before every experiment, cells were washed 5 times with warm PBS, in both compartments. Supernatant of both compartments was collected 24 hours after serotonin treatment. Detection of insulin was possible only in the upper compartment (Figure 5G), suggesting that any insulin produced in the ChP is secreted at its CSF-facing apical membrane.

Apical and/or basolateral membrane responsiveness to serotonin was evaluated by adding serotonin either to the upper or lower compartment. An increase in insulin concentration in the supernatant was observed only when serotonin was added to the upper compartment (Figure 5G), suggesting that this is the apical localization of the serotonin receptor 2C. Indeed, HTR2C IF staining only at the apical surface of the $\mathrm{ChP}$ (Figure $5 \mathrm{~F}$ ) supports that observation, suggesting that the EChP respond to CSF serotonin levels.

Even though EChP express both glucose transporter 2 (GLUT2) and glucokinase (GCK), albeit in very low concentrations compared with $\beta$ cells (data not shown), glucose stimulation does not lead to cell depolarization and $\mathrm{Ca}^{2+}$ influx through voltage-gated channels. Instead, $\mathrm{iCa}^{2+}$ is mobilized when serotonin, present in the CSF, binds to HTR2C, leading to IP3 formation and opening of IP3-gated $\mathrm{Ca}^{2+}$ channels in the ER, finally resulting in insulin secretion (Figure $5 \mathrm{H}$ ).

Brain serotonin levels regulate insulin expression in the ChP. Finally, in order to validate our hypothesis at a physiological level, in vivo ablation of the neuronal serotonin system was achieved by stereotaxic injection of 5,7-dihydroxytryptamine (5,7-DHT), a neurotoxin known to damage and eventually kill serotonergic and noradrenergic neurons. The neurotoxin was injected into the dorsal raphe nucleus (DRN), one of the 
A
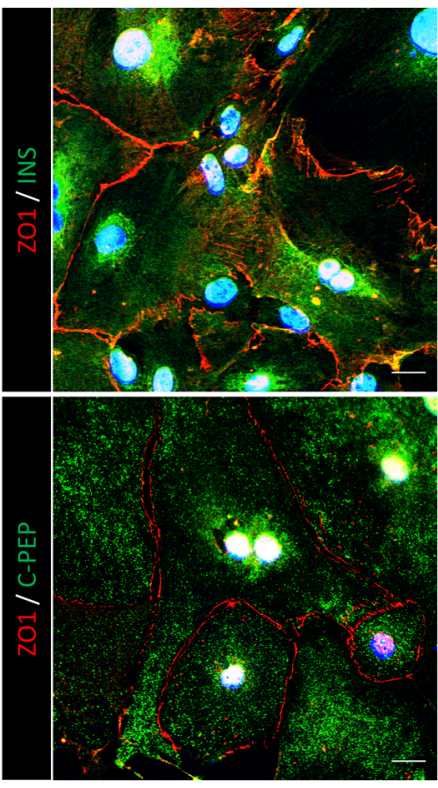

B

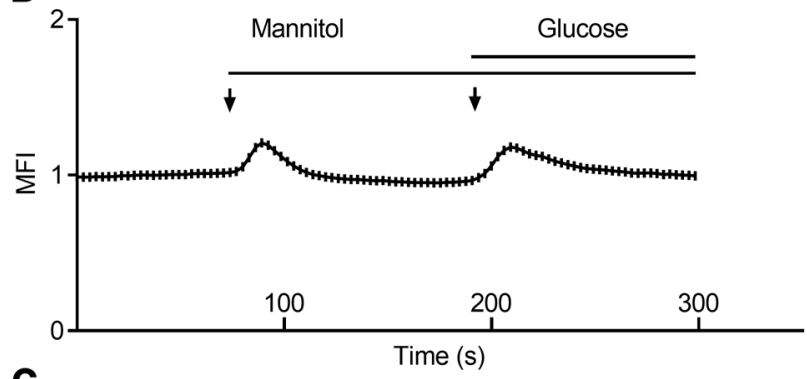

C
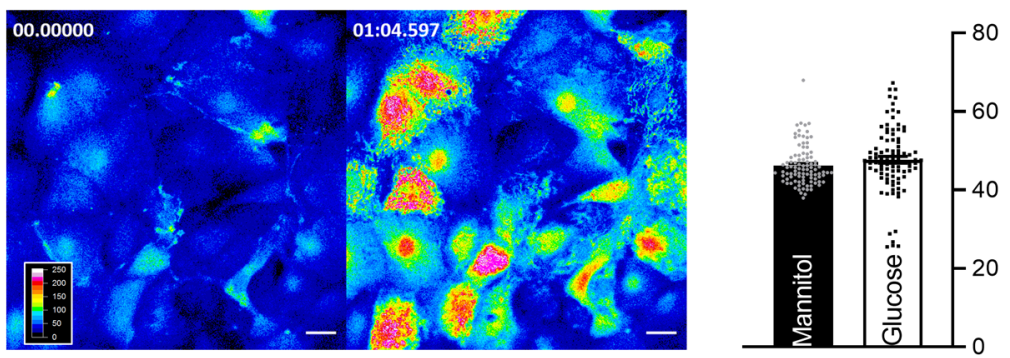

$\stackrel{\cup}{\gtrless}$

D

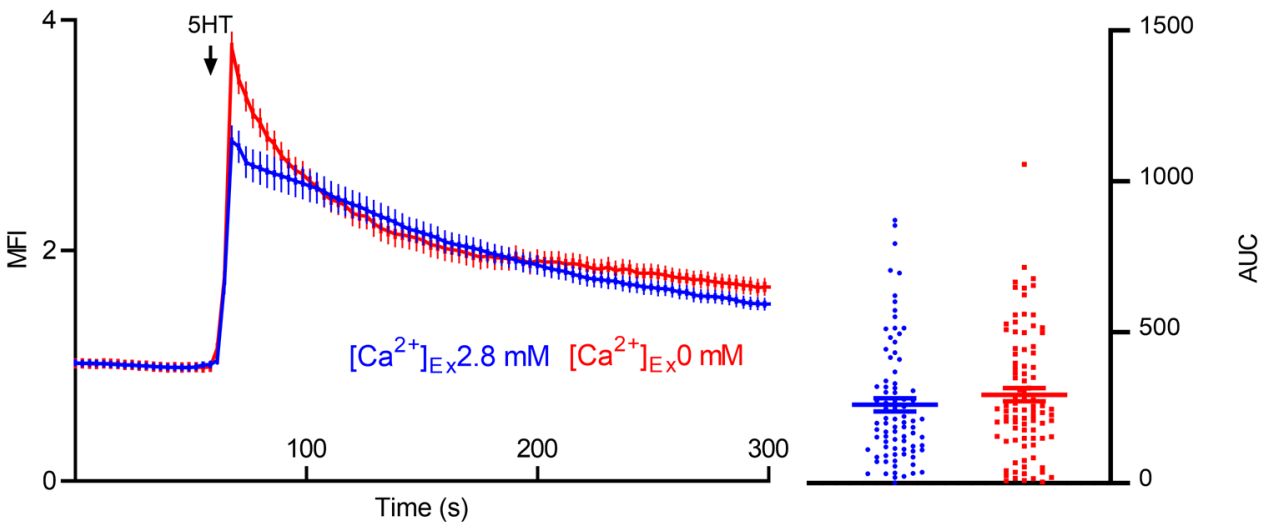

$\mathbf{E}$

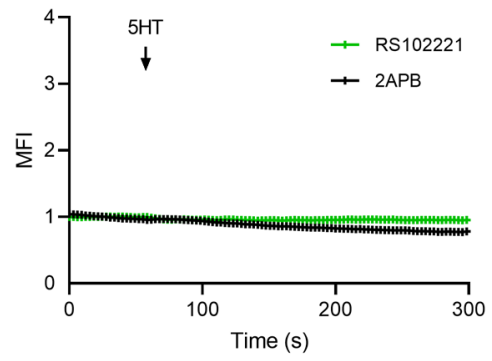

Figure 4. Serotonin causes intracellular $\mathrm{Ca}^{2+}$ oscillation in cultured choroid plexus primary epithelial cells. (A) In culture, epithelial cells of the choroid plexus form tight junctions, as shown by Z0-1 staining (red), and insulin and C-peptide are still detectable (green). Scale bars: $20 \mu \mathrm{m}$. (B) Glucose had no effect on $\mathrm{CC}^{2+}$ levels, as shown by live cell $\mathrm{Ca}^{2+}$. (C and D) Serotonin, on the other hand, induced an acute intracellular increase (average peak intensity of 2.951 times higher than baseline, SEM $=0.135, n=87,8$ independent experiments). Extracellular $\mathrm{Ca}^{2+}$ was not necessary for such effect (average peak intensity of 3.757 times higher than baseline, $\mathrm{SEM}=0.144, n=96,7$ independent experiments), as evidenced by equal AUC of responses with or without extracellular $\mathrm{Ca}^{2+}$ (cells with extracellular $\mathrm{Ca}^{2+}$ : total peak area $=249.5$; standard error $=17.99 ; 95 \% \mathrm{Cl}, 214.3-284.8$; and cells without extracellular $\mathrm{Ca}^{2+}:$ total peak area $=269.3 ; \mathrm{SEM}=19.68 ; 95 \% \mathrm{Cl}, 230.8-307.9$; t test $\mathrm{p}$ value $=0.4596)$. Scale bars: $20 \mu \mathrm{m} .(\mathrm{E})$ Pharmacological antagonism of IP3R with 2APB, or membrane serotonin receptor 5HT2C with RS 102221, completely blocked the serotonin-induced $\mathrm{Ca}^{2+}$ increase in these cells.

3 major serotonergic nuclei in the brain. Toxic selectivity of serotonergic system was ensured with an i.p. injection of desipramine $(25 \mathrm{mg} / \mathrm{kg}) 20$ minutes before stereotaxic injection of 5,7-DHT, effectively protecting catecholaminergic neurons.

As shown in Figure 6, A and B, by immunostaining, 5,7-DHT injection successfully damaged the serotonergic neurons in the DRN. qPCR analysis of RNA extracted from the ChP of these animals revealed a reduction in Ins2 levels both in the lateral and 4thV choroid plexi (Figure 6C), proving that brain serotonin levels play a role in the regulation in the $\mathrm{ChP}$ insulin expression. Surprisingly, we also observed a reduction in $5 \mathrm{HT} 2 \mathrm{C}$ receptor expression levels in the $\mathrm{ChP}$ of the lateral ventricles (Figure 6D). 

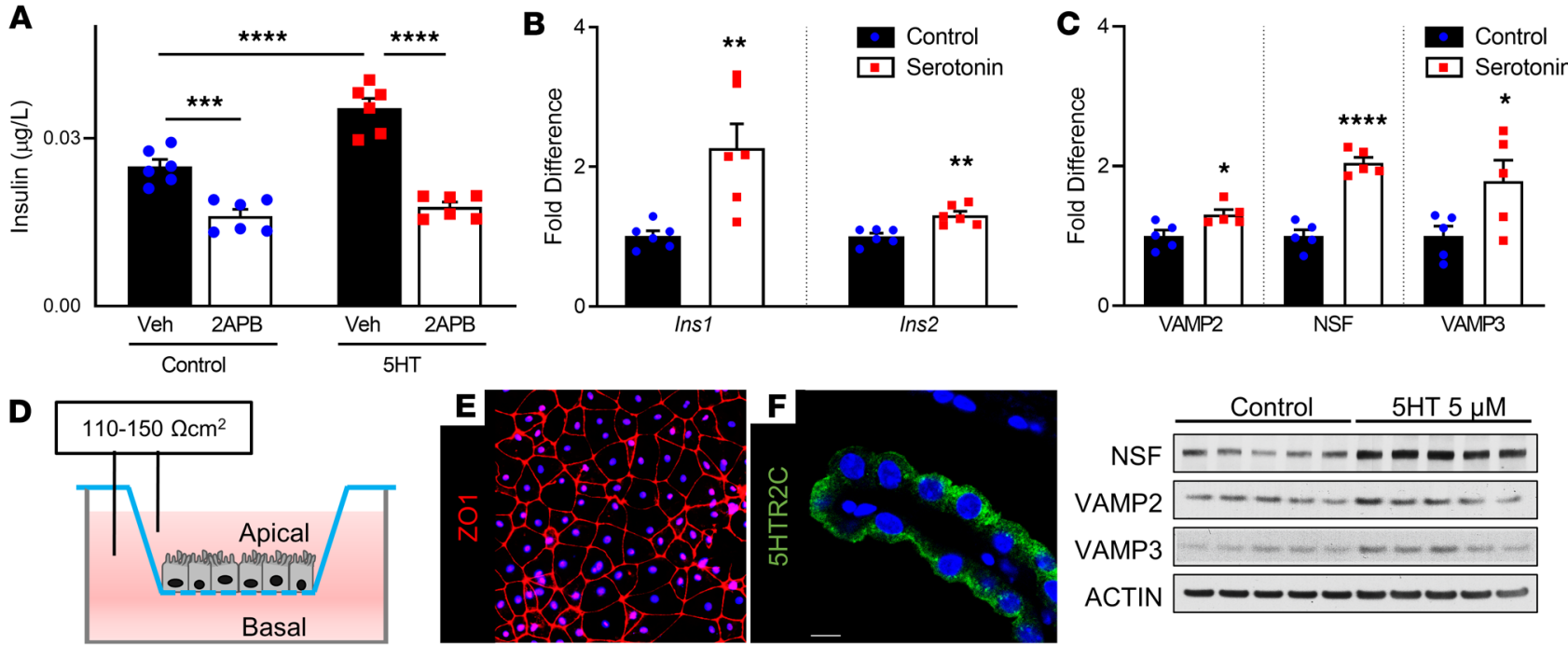

G

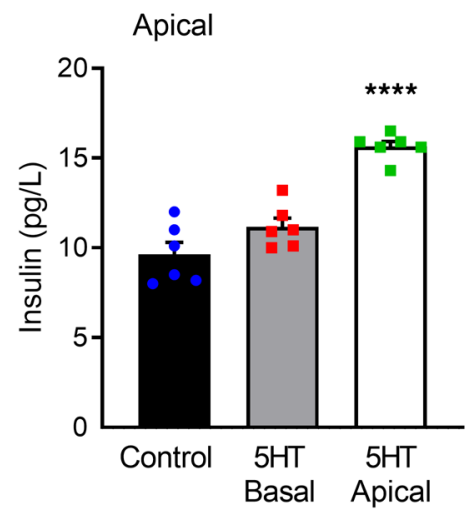

H

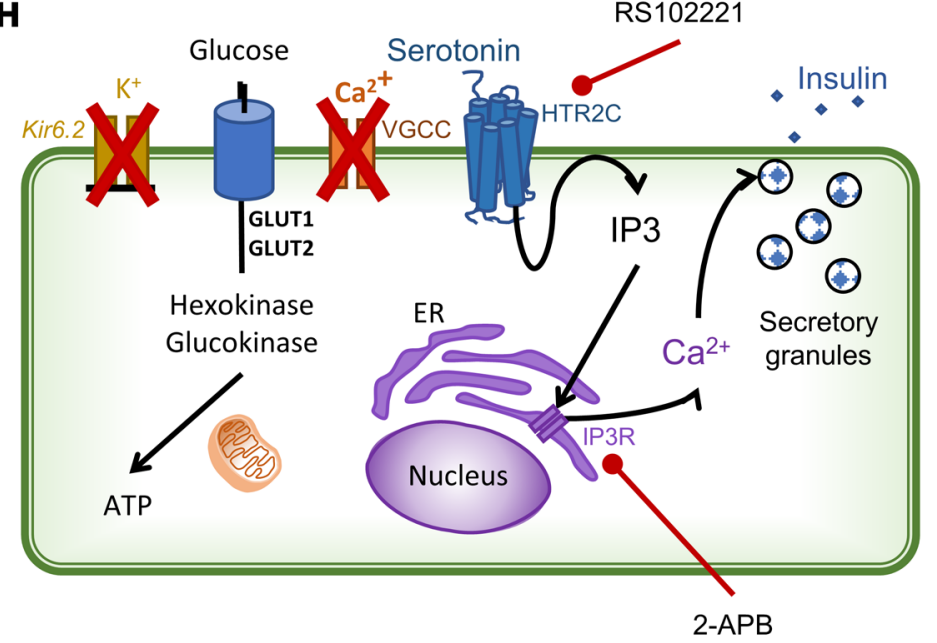

Figure 5. CSF serotonin induces choroid plexus insulin secretion in a $\mathbf{C a}^{2+}$-dependent way. (A) Levels of insulin released in the culture media were increased by serotonin treatment, while IP3R antagonism had the opposite effect. (Control: mean $=0.02498$, SEM = 0.001259; 5HT: mean = 0.03540, SEM $=0.001746 ; 2 \mathrm{APB}:$ mean $=0.01613, \mathrm{SEM}=0.001180 ; 5 \mathrm{HT}+2 \mathrm{APB}$ : mean $=0.01775, \mathrm{SEM}=0.0008521 ; n=6$ independent cell cultures). One-way ANOVA with Tukey's multiple comparisons test, ${ }^{* *} P<0.001 ;{ }^{* * *} P<0.0001$. (B) Insulin gene expression was also positively affected by serotonin treatment (Ins1: control mean $=1.013, \mathrm{SEM}=0.07246,5 \mathrm{HT}$ mean $=2.268, \mathrm{SEM}=0.3460, n=6$ independent cell cultures, $P=0.0053$; Ins2: control mean $=1.006, \mathrm{SEM}$ $=0.04640,5 \mathrm{HT}$ mean $=1.307, \mathrm{SEM}=0.05719, n=6$ independent cell cultures, $P=0.0284)$. Student's $t$ test, ${ }^{* *} P<0.01$. (C) Levels of vesicle-associated proteins were also elevated by serotonin treatment (NSF: control $=1.0 \pm 0.08828 \mathrm{SEM}, 5 \mathrm{HT}=2.272 \pm 0.08034 \mathrm{SEM}, n=5$ independent cell cultures, $P<$ 0.0001; VAMP2: control $=1.0 \pm 0.08333 \mathrm{SEM}, 5 \mathrm{HT}=1.310 \pm 0.06804 \mathrm{SEM}, n=5$ independent cell cultures, $P=0.0205$; VAMP3: control $=1.0 \pm 0.1422$ SEM, $5 \mathrm{HT}=1.785 \pm 0.2997 \mathrm{SEM}, n=5$ independent cultures, $P=0.0455$ ). Student's $t$ test, ${ }^{*} P<0.05 ;{ }^{* * *} P<0.0001$. (D and $\mathbf{E}$ ) Culture of EChP in the transwell system creates 2 isolated compartments, characterized by elevated transepithelial resistance, due to formation of tight junctions between the cells (ZO1, red). (F) 5HTR2C is localized on the apical membrane of the choroid plexus epithelium (green). Scale bar: $10 \mu \mathrm{m}$. (G) Serotonergic stimulation of the apical, but not basal, membrane increases insulin concentration in the culture media (control: mean $=9.633 \mathrm{pg} / \mathrm{L}, \mathrm{SEM}=0.6756 ; 5 \mathrm{HT}$ apical: $\mathrm{mean}=15.63 \mathrm{pg} / \mathrm{L}$, $\mathrm{SEM}=0.2985 ; n=6$ independent cell cultures). One-way ANOVA, ${ }^{* * *} P<0.0001$. (H) Proposed mechanism of serotonergic regulation of insulin secretion in epithelial cells of the choroid plexus.

\section{Discussion}

Insulin signaling in the brain is implicated in healthy cognitive function and its decline with aging and neurodegeneration. Although it has been long hypothesized that insulin is able to cross the blood brain barrier (BBB) through a saturable transport system, said mechanism is limited and inefficient. In that sense, local insulin production within the brain tissue seems to be a possibility, but scientific reports addressing this question are still surrounded by controversy. As such, conclusive identification of an insulin source in the brain would not only allow us to better understand the importance of insulin in brain physiology, but it could also point to a new therapeutic target for dementia and age-related cognitive disorders. 
Using FISH for Ins 2 mRNA in sagittal sections of mouse brains, we show that brain insulin mRNA is predominantly expressed not in the brain parenchyma, but in the epithelial layer of the ChP, where we also detected expression of enzymes needed for maturation of preproinsulin into its mature, bioactive form. In agreement with our findings, Ins 2 expression by EChP was also detected by single-cell RNA sequencing, as described recently by Dani et al. (37).

We detected immunoreactive insulin and C-peptide in the ChP of mice and humans, as well as in primary cultured mouse EChP. To our knowledge, this is the first report of insulin production in ChP. Previous work with insulin reporter genetic models demonstrated Ins 2 expression in murine $\mathrm{ChP}(38,39)$ but no Ins 2 promoter activity in any other brain structure. These models, however, failed to detect insulin mRNA or its corresponding protein. Conversely, several studies using mice with Cre expression driven by the rat insulin promoter (RIP-Cre) describe strong Cre expression in hypothalamic neurons (40, 41). However, RIP-Cre mice use a short portion (448 bp) of the rat Ins2 gene promoter to drive Cre expression (42), which makes them susceptible to ectopic expression due to unspecific promoter activity.

Unlike $\beta$ cells, glucose stimulation did not influence insulin secretion in cultured EChP, failing to elicit any $\mathrm{iCa}^{2+}$ response. Indeed, $\mathrm{ChP}$ epithelial cells do not express Kir6.1 and Kir6.2, necessary for the formation of the ATP-sensitive $\mathrm{K}^{+}$channel, nor do they contain voltage-gated $\mathrm{Ca}^{2+}$ channels (43). Instead, we found that activation of the serotonergic receptor $5 \mathrm{HT} 2 \mathrm{C}$ causes $\mathrm{iCa}^{2+}$ mobilization mediated by IP3Rs in the ER, ultimately culminating in insulin release. Also absent is the IAPP, expressed and cosecreted with insulin in $\beta$ cells (44). Blood-derived IAPP can be found throughout the brain (45), and high-affinity IAPP binding sites are found in circumventricular organs with leaky capillaries, such as the area postrema, nucleus of the solitary tract, and hypothalamus (46). However, Li and colleagues reported IAPP mRNA and protein in hypothalamic neurons, suggesting for the first time to our knowledge that IAPP is produced in the brain (47). However, using the same IAPP antibody and qPCR primers, we could not detect either mRNA or immunoreactive IAPP in ChP of mice or humans.

Another relevant difference between $\mathrm{ChP}$ and $\beta$ cell insulin production is the content of specific Ins 2 splicing variants. Mouse Ins2 gene splicing produces 3 variants, Ins2-1, Ins2-2, and Ins2-3 (34), that encode the same preproinsulin protein coding region. However, they differ in their 5 ' untranslated region (5'-UTR). While Ins2-2 is the predominant variant in pancreatic islets, Ins2-1 and Ins2-3 are the predominant isoforms in EChP. The 5'-UTR of Ins 2 splicing variants might be involved in differential translation efficiency and subcellular localization of insulin in $\beta$ cells and ChP. Exploring these differences might help us to better understand the role of $\mathrm{ChP}$-derived insulin and the mechanisms regulating its expression and production.

Even though the $\mathrm{ChP}$ has a high density of serotonergic receptors (48), of which 5HT2C is the most abundant, serotonin effects on $\mathrm{ChP}$ activity is still largely debated. Intracerebroventricular injection of serotonin seems to have a negative effect on CSF production (49), while elevations in blood serotonin levels increase blood flow to the $\mathrm{ChP}(50)$. These seemingly paradoxical findings indicate a disconnect between blood supply and metabolism of EChP. In fact, activation of 5HT2C in EChP has been associated with a decrease in carbonic anhydrase (51) and $\mathrm{Na}^{+} / \mathrm{K}^{+}$pump (52) activities, leading to a negative effect on CSF formation in both cases. The epithelial layer of the $\mathrm{ChP}$ and its associated vasculature are stimulated by cholinergic and adrenergic innervations (53), and evidence in rats support the idea that serotonergic nerves may also be present in the $\mathrm{ChP}(54,55)$. Another possible source might be serotonergic fibers and terminals located over the ependymal layer lining the ventricles (56). These nerve terminals do not form classic synapses; instead, they are thought to release serotonin directly in the CSF (57), where it could diffuse and act on the nearby $\mathrm{ChP}$. This network of fibers, known as supra- and subependymal plexus, is composed mainly of serotoninergic nerve terminals originating from the raphe nuclei in the brainstem (58).

We show that serotonergic neurons from the DRN modulate insulin expression in the ChP, and serotonin induces insulin release from the EChP. A relationship between serotonin and insulin is already very well described in other systems. In pancreatic islets, for example, $\beta$ cell mass and insulin release during pregnancy are reported to be regulated by serotonin $(59,60)$. In the hypothalamus, levels of extracellular serotonin and insulin increase after feeding $(61,62)$, and notably, local induction of serotonergic activity in the ventromedial hypothalamus/paraventricular nucleus (VMH/PVN) acutely increases extracellular insulin in the hypothalamus, without any peripheral effect on either circulating insulin or glucose levels (63). Furthermore, alloxan-induced diabetic rats treated with fluoxetine, a serotonin reuptake inhibitor, had higher brain insulin levels than nontreated rats (64). Taken together, these findings support our results showing that serotonin may be a regulator of insulin levels in the brain and, more specifically, in the ChP. 
A

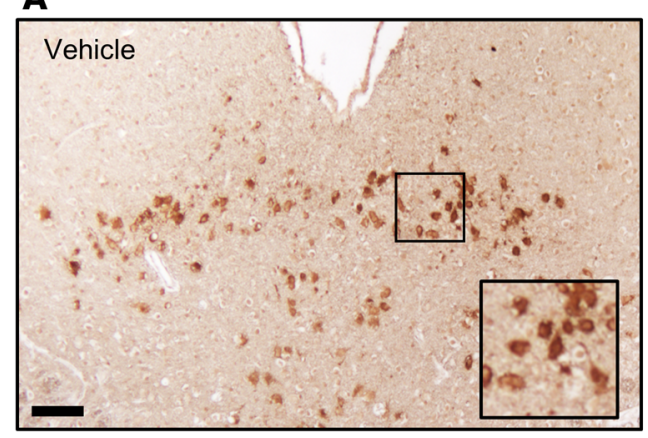

B

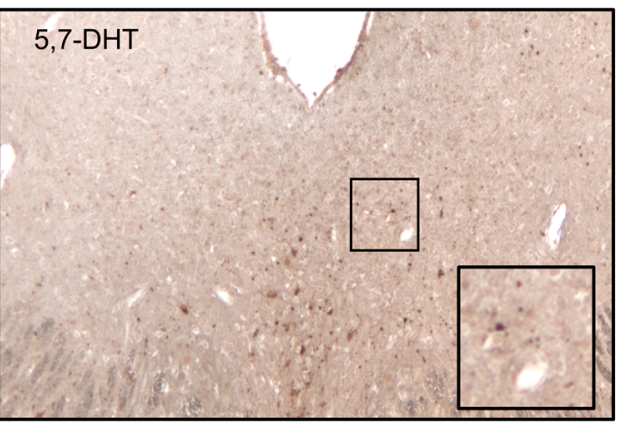

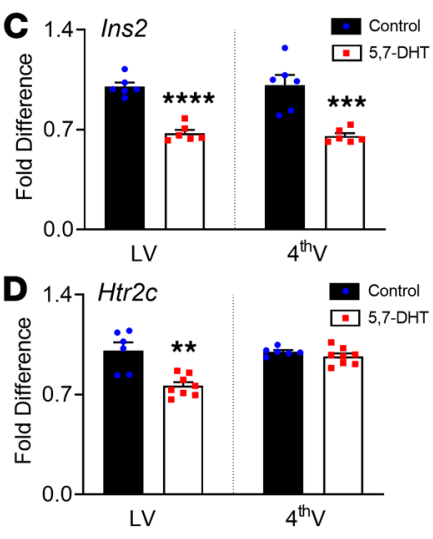

Figure 6. Serotonergic neurons from the dorsal raphe nucleus regulate insulin expression in the choroid plexi. (A and B) Chemical selective ablation of serotonergic neurons of the dorsal raphe nucleus was achieved by stereotaxic injection of 5,7-DHT, effectively killing any serotonin-producing cell. Scale bar: $50 \mu \mathrm{m}$. (C) Denervation of $5 \mathrm{HT}$ neurons had a negative effect on the expression of the Ins2 gene in both the lateral ventricle and 4 thV choroid plexi (LV ChP: control = $1.0 \pm 0.02807$ SEM; 5,7-DHT = 0.6751 $\pm 0.02371, n=6$ mice; 4thV ChP: control = 1.0 \pm 0.07107 SEM; 5,7-DHT = 0.6549 $\pm 0.01983, n=6$ mice) Student's $t$ test; ${ }^{* *} P<0.001,{ }^{* * *} P<0.0001$ ). (D) mRNA levels of serotonin receptor $2 \mathrm{C}$ remained the same in the hindbrain choroid plexus, while a slight decrease of was observed in the lateral ventricle choroid plexus (Htr2c LV ChP mean $=1.008, \mathrm{SEM}=0.05715 ; 4$ thV ChP mean $=0.7613, \mathrm{SEM}=0.02604, n=$ 6-8 mice, $P=0.0010$ ). Student's $t$ test, ${ }^{* *} P<0.01$.

The ChP also has a high density of insulin receptors (65), whose activity might have a positive effect on CSF formation. Insulin induces $\mathrm{Na}^{+} / \mathrm{H}^{+}$exchanger (NHE) activity in different cells $(66,67)$. In the $\mathrm{ChP}$, activation of NHE by insulin induces an increase in intracellular $\mathrm{Na}^{+}$concentrations, culminating in higher $\mathrm{K}^{+}$and $\mathrm{Cl}^{-}$apical efflux, which is then followed by $\mathrm{H}_{2} \mathrm{O}$ diffusion (68). Additionally, insulin signaling in the $\mathrm{ChP}$ is capable of inhibiting $5 \mathrm{HT} 2 \mathrm{C}$ receptor signal transduction in a MAPK-dependent way (69). As such, a possible explanation of our findings could be that an integrated negative feedback loop exists, wherein the $\mathrm{ChP}$ responds to serotonergic stimulation by releasing insulin, which in turn acts in an autocrine/paracrine way to terminate $5 \mathrm{HT} 2 \mathrm{C}$ intracellular signaling.

For many years, it has been thought that insulin receptors transport blood-derived insulin across endothelial cells in brain capillaries. In the last few years, however, this idea has been challenged. Insulin is found in the brain parenchyma, even when the insulin receptor is genetically nullified in brain endothelial cells or when the insulin receptor is pharmacologically blocked $(70,71)$, adding to the controversy surrounding peripheral insulin penetrance into the CNS. The identification of a major insulin source within the brain, as seems to be the case for the $\mathrm{ChP}$, points to a more promising target for therapeutic manipulation of insulin delivery to the brain.

In conclusion, brain insulin is synthesized in $\mathrm{EChP}$ and is actively secreted in response to increased $\mathrm{iCa}^{2+}$ levels, such as occurs after activation of plasma membrane $5 \mathrm{HT} 2 \mathrm{C}$ receptors, but not glucose. Studies attempting to understand and describe which stimuli and pathways are capable of modulating production and release of factors produced by the $\mathrm{ChP}$ are still needed. This could help us better comprehend the role of $\mathrm{CSF}$ and $\mathrm{ChP}$ in brain physiology and could have profound implications in how we understand and treat neurological and neurodegenerative diseases.

\section{Methods}

Primary culture of EChP. Primary culture of EChP from C57BL/6J mice was performed as previously described elsewhere (72). Briefly, P1-P5 newborn mice were decapitated, and brains were submerged in ice-cold HBSS with $\mathrm{Ca}^{2+}$ and $\mathrm{Mg}^{2+}$ (Thermo Fisher Scientific), supplemented with $0.6 \%$ sucrose. ChP from $\mathrm{LV}$ and $4 \mathrm{thV}$ were removed and transferred to a microcentrifuge tube containing $500 \mu \mathrm{L}$ of the same solution and maintained on ice throughout the entirety of the dissection step. Enzymatic digestion of the tissue was achieved by adding $500 \mu \mathrm{L}$ of a $2000 \mathrm{U} / \mathrm{mL}$ type II collagenase (Thermo Fisher Scientific) solution (final collagenase activity concentration $1000 \mathrm{U} / \mathrm{mL}$ ) and incubated for 40 minutes at $37^{\circ} \mathrm{C}$ under constant agitation. After mechanical trituration, the suspension containing single cells and small tissue clumps was centrifuged for 3 minutes at $800 \mathrm{~g}$, the supernatant was discarded, and pellet was resuspended in $1 \mathrm{~mL}$ of TrypLE (Thermo Fisher Scientific). This solution was incubated for 5 minutes at $37^{\circ} \mathrm{C}$ under constant 
agitation, triturated, and centrifuged once again at $800 \mathrm{~g}$ for 3 minutes. Supernatant containing TrypLE was discarded, and the cell pellet was resuspended in complete media composed of DMEM/F-12 mixture (Thermo Fisher Scientific) supplemented with 10\% FBS and 1\% antibiotic-antimycotic solution (Thermo Fisher Scientific; penicillin $100 \mathrm{U} / \mathrm{mL}$, streptomycin $100 \mu \mathrm{g} / \mathrm{mL}$, and amphotericin B $0.25 \mu \mathrm{g} / \mathrm{mL}$, final concentrations). For plating on glass coverslips or Transwell (Corning) membrane, cellware was coated with laminin (Thermo Fisher Scientific; $1 \mu \mathrm{g} / \mathrm{mL}$ laminin solution in HBSS) at $37^{\circ} \mathrm{C}$ for 2 hours prior to cell plating, after which laminin solution was discarded and cell suspension was immediately added. Fibroblast growth inhibition was obtained by addition of cytosine arabinoside (Sigma-Aldrich) in a final concentration of $20 \mu \mathrm{M}$ for the first 4-5 days in culture. Unlike other cell types, such as fibroblasts, EChP are unaffected by cytosine arabinoside due to expression of a nucleoside transport system that does not recognize arabinosides as substrate (73). Complete media changes were performed every 2-3 days.

RNAscope FISH. Insulin mRNA in brain sections was detected by FISH. RNAscope probes for mouse Ins2 and Iapp was customer designed (Ins2: $10 \mathrm{ZZ}$ pairs targeting 2-470 nucleotide sequence of NM_008387.5 named Mm-Ins2-O1-C2; Iapp: 13 ZZ pairs targeting 8-706 nucleotide sequence of NM_010491.2 named Mm-Iapp-C2) by Advanced Cell Diagnostics Inc. (ACD) in C2 channel. Probe for mouse Ttr (20 ZZ pairs targeting 141-1149 nucleotide sequence of NM_013697.5) in C1 channel (Mm-Ttr; catalog 424171) were ordered from ACD. Freshly dissected mouse brains were immediately embedded in OCT, snap frozen in liquid nitrogen, and stored at $-80^{\circ} \mathrm{C}$ in a sealing bag before use. Sections $(15 \mu \mathrm{m})$ were obtained in a cryostat microtome and then fixed with 10\% neutral buffered formalin (NBF) right before hybridization and staining steps. Pretreatment of brain sections, probe reactions, and labeling were performed according to RNAscope Multiplex Fluorescent Detection Kit v2 protocol, as previously described (74). The negative control probe was a universal control probe targeting bacterial Dapb gene (accession no. EF191515) from the Bacillus subtilis strain, and the positive controls were probes targeting mouse $U b c$ (ubiquitin C), $P p 1 b$ (Cyclophilin B), and Polr2a (DNA-directed RNA polymerase II subunit RPB1). Images were acquired using a Zeiss LSM 880 confocal microscope.

Gene expression analysis by $q P C R$. RNA from either ChP or primary EChP cell pellets was extracted by affinity chromatography using PicoPure RNA isolation kit (Thermo Fisher Scientific). RNA quality and purity were assessed in a NanoDrop spectrophotometer (Thermo Fisher Scientific) and Bioanalyzer RNA 6000 nanochip (Agilent). Up to $2 \mu$ g of total RNA were reverse transcribed into cDNA using qScript XLT cDNA SuperMix (QuantaBio). Resulting cDNA was diluted (2.5-50 times) according to target abundance. Duplex qPCR assays were performed on technical duplicates using a fluorescein amidite-labeled (FAM-labeled) target probe (Table 2) and a VIC-labeled mouse $\beta$-actin as an endogenous control, with TaqMan Advanced Fast PCR Master Mix (Thermo Fisher Scientific). qPCR reactions were run in a StepOnePlus Real Time System using the default program. The relative fold change was calculated by the $\Delta \Delta \mathrm{Ct}$ method.

Evaluation of Ins 2 specific splicing variants was made using custom-made primers and minor groove binder (MGB) probes with the following sequences: Ins2-1 (forward [F]: 5' - CCGCTACAATCAAAAACCATCA - 3'; reverse [R]: 5' - GAGCCAGGCCCACTGAGA - 3'; TaqMan probe: 5' - CAAGCAGGAAGGTACTC - 3'); Ins2-2 (F: same as Ins2-1; R: 5' - CATCCACAGGGCCATGTTG - 3'; TaqMan probe: 5 - CAAGCAGGAAGGTTATTGT - 3'); and Ins2-3 (F: 5' - CCAGTAACCACCAGCCCTAAGT - 3'; R: 5 - AGATAGGCTTCCTGCTTGCTGATG - 3'; TaqMan probe: 5' - ATCCGCTACAATCAA - 3').

$I H C$ and IF. For brain sections, C57BL/6J male mice were transcardiacally perfused with ice-cold PBS followed by ice-cold PFA. Brains were removed and postfixed in PFA for 4 additional hours, after which they were maintained in PBS. Whole brains were dehydrated, paraffin embedded, and coronally sectioned $(10 \mu \mathrm{m})$. Slides were deparaffinized in xylene, and sections were rehydrated in successive incubations with decreasing ethanol concentration. Heat-induced epitope retrieval was performed by placing the slides in citrate buffer ( $\mathrm{pH}$ 7.0) and heating them to subboiling temperatures for 10 minutes in a microwave. Sections used for DAB staining were then treated with hydrogen peroxide in order to block endogenous peroxidase activity. All slides were incubated in a blocking solution consisted of $10 \%$ normal donkey serum (whole antiserum, Abcam) in PBS, and primary antibody incubation was performed overnight at $4^{\circ} \mathrm{C}$. After washes, sections were incubated in their respective secondary antibody solutions. IHC staining was amplified using the biotin-avidin system (Vector Laboratories) and then developed with a DAB and hydrogen peroxide kit (Vector Laboratories). For IF, we used Alexa Fluor-conjugated secondary antibodies (Thermo Fisher Scientific). The complete list of primary antibodies used for IHC/IF can be found in Table 3. Antibody against amylin (IAPP), originally developed by Amylin Pharmaceuticals, was a gift from James Trevaskis 
Table 2. TaqMan probes used for qPCR analysis

\begin{tabular}{lcc}
\hline Symbol & Gene name & TaqMan assay ID \\
Ins1 & Insulin I & Mm01950294_s1 \\
\hline Ins2 & Insulin II & Mm00731595_g1 \\
Iapp & Amylin & Mm00439403_m1 \\
Pcsk1 & Proprotein convertase subtilisin/kexin type 1 & Mm00479023_m1 \\
Pcsk2 & Proprotein convertase subtilisin/kexin type 2 & Mm00500981_m1 \\
Htr2c & 5-hydroxytryptamine (serotonin) receptor 2C & Mm00434127_m1 \\
Insr & Insulin receptor & Mm01211875_m1 \\
Actb & $\beta-A c t i n$ & Mm00607939_s1
\end{tabular}

(Gilead Sciences, San Francisco, California, USA). IHC pictures were taken in an Olympus IX51 microscope, and IF images were acquires using a Zeiss 880 LSM confocal microscope. For IF of EChP, cells were fixed for 15 minutes in methanol 100\% (Sigma-Aldrich), permeabilized with PBS (Thermo Fisher Scientific) plus $0.3 \%$ Triton-X (Sigma-Aldrich), and blocked and incubated in antibody solutions as described above. Formalin-fixed, paraffin-embedded human ChP slices were obtained from GeneTex (catalog GTX24298), from an adult male.

Western blotting. ChP tissue or primary EChP cell pellets were homogenized in RIPA lysis buffer with protease and phosphatase inhibitors $(20 \mathrm{mM}$ Tris- $\mathrm{HCl}, 150 \mathrm{mM} \mathrm{NaCl}, 1 \mathrm{mM}$ Na2EDTA, $1 \mathrm{mM}$ EGTA, $1 \%$ NP-40, 1\% sodium deoxycholate, $2.5 \mathrm{mM}$ sodium pyrophosphate, $1 \mathrm{mM} \beta$-glycerophosphate, $1 \mathrm{mM}$ sodium orthovanadate, and mini protease inhibitor cocktail, cOmplete, Roche). Lysate protein concentration was evaluated by Bradford's colorimetric assay. Protein samples were fractionated by SDS-PAGE and transferred to a nitrocellulose membrane, which was then incubated with a 5\% BSA solution in TBST (10 mM Tris, $\mathrm{pH} 8.0,150 \mathrm{mM} \mathrm{NaCl}, 0.5 \%$ Tween 20) for 2 hours. Membranes were incubated in primary antibody solution (TBST, 1\% BSA) with antibodies against STX1A (Cell Signaling Technology, 18572), VAMP2 (Cell Signaling Technology, 13508), VAMP3 (Cell Signaling Technology, 61451), NSF (Cell Signaling Technology, 3924), SNAP25 (Cell Signaling Technology, 5309), SYT1 (Cell Signaling Technology, 14558), and klotho (KL) (R\&D Systems, AF1819) at $4^{\circ} \mathrm{C}$ overnight. All primary antibodies were used at a 1:500 concentration. Antibody against $\beta$-actin (1:2000, Cell Signaling Technology, 3700) was used as an endogenous control. All primary antibodies, with the exception of KL (R\&D Systems) were purchased from Cell Signaling and used in a 1:500 dilution. Antibody against $\beta$-actin (1:2000, Cell Signaling Technology) was used as a control. The complete list of antibodies used for Western blotting assays can be found in Table 4. Membranes were then washed 3 times with TBST and incubated with secondary antibody solution (TBST, 1\% BSA) containing horseradish peroxidase-conjugated antibodies anti-rabbit IgG-Fc (Cell Signaling Technology, 7074, 1:4000) for 2 hours. After 3 washes with TBST, membranes were developed using an ECL system (Pierce ECL Western Blotting Substrate, Thermo Fisher Scientific). Values are presented as relative optical density, normalized by average of controls.

Live cell $\mathrm{Ca}^{2+}$ imaging. EChP were plated on glass-bottomed $35 \mathrm{~mm}$ dishes (MatTek) and cultured for 1 week as described above. For $\mathrm{Ca}^{2+}$ imaging, culture media was discarded, and cells were washed 3 times with PBS and incubated for 30 minutes with $5 \mu \mathrm{M}$ Fluo-8 (Thermo Fisher Scientific) diluted in artificial CSF (aCSF) ( NaCl 119 mM, KCl 2.5 mM, NaHCO 26 mM, NaH$P_{2} P_{4} 1 \mathrm{mM}$, glucose $11 \mathrm{mM}$, HEPES 10 $\mathrm{mM}, \mathrm{MgCl}_{2} 2 \mathrm{mM}, \mathrm{CaCl}_{2} 2.8 \mathrm{mM}$ ) (Sigma-Aldrich). After incubation, cells were rinsed twice with aCSF with or without $\mathrm{Ca}^{2+}\left(\mathrm{NaCl} 119 \mathrm{mM}, \mathrm{KCl} 2.5 \mathrm{mM}, \mathrm{NaHCO}_{3} 26 \mathrm{mM}, \mathrm{NaH}_{2} \mathrm{PO}_{4} 1 \mathrm{mM}\right.$, glucose $11 \mathrm{mM}$, HEPES $10 \mathrm{mM}, \mathrm{MgCl}_{2} 4.8 \mathrm{mM}$, EGTA $0.5 \mathrm{mM}$ ) and maintained in the same media for confocal imaging. Antagonism of either IP3R or $5 \mathrm{HT} 2 \mathrm{C}$ receptor was achieved by a 10 -minute preincubation with $2 \mathrm{APB}$ (Tocris) $150 \mu \mathrm{M}$ or RS102221 (Tocris) $50 \mu \mathrm{M}$, respectively. Antagonists were still present in the media at the time of the recordings. For all experiments, a baseline of at least 1 minute was recorded before stimulus with serotonin (Tocris) at a final concentration of $5 \mu \mathrm{M}$. Live imaging was obtained using an LSM 510 confocal microscope, with excitation at $488 \mathrm{~nm}$ and emission at approximately $525 \mathrm{~nm}$. Mean fluorescence intensity of areas corresponding to individual cells was calculated every 3 seconds.

Transwell culture of EChP primary cells. Primary epithelial cell suspension from the ChP of newborn mice was obtained as described above and plated on 6-well polyethylene terephthalate (PET) transwell 
Table 3. Primary antibodies used for IHC and IF

\begin{tabular}{lcccc}
\hline Target & Manufacturer & Host & Catalog & RRID \\
Insulin & DAKO (now Agilent) & Guinea pig & A0564 & AB_2617169 \\
C-peptide & Abcam & Rabbit & ab14181 & AB_300968 \\
ZO-1 & Thermo Fisher Scientific & Rabbit & PA5-85256 & AB_2792399 \\
HTR2C & Thermo Fisher Scientific & Rabbit & PA5-27164 & AB_2544640 \\
Serotonin & Immunostar & Rabbit & 5HT & AB_2313880 \\
IAPP (Amylin) & Amylin Pharmaceuticals & Mouse & Clone F025-27.4 &
\end{tabular}

ANot commercially available. RRID, Research Resource Identifier.

membrane inserts with $0.4-\mu \mathrm{m}$ pores, precoated with laminin. Media was changed on both upper and lower compartments every 2-3 days, until cells reached confluency. Confluent monolayer formation was verified under the microscope and confirmed with TEER readings between $100-150 \Omega \mathrm{cm}^{2}$, using Millicell ERS2 voltohmmeter (MiliporeSigma). After becoming confluent, cells were thoroughly washed 5 times with aCSF by replacing media from both compartments. Serotonin was added at a final concentration of $5 \mu \mathrm{M}$ either at the upper (CSF facing) or lower (blood facing) compartment. After 24 hours, media from each compartment was collected and centrifuged for 10 minutes at $1000 \mathrm{~g}$, and supernatant was lyophilized overnight. Lyophilisate was resuspended in Mercodia Diabetes Sample Buffer in 1/10 of its original volume (upper compartment lyophilisate in $150 \mu \mathrm{L}$ and lower compartment in $250 \mu \mathrm{L}$ ), and insulin concentration was measured with Mercodia Ultrasensitive Mouse Insulin ELISA kit.

DRN lesion. Ablation of central serotonergic neurons was achieved by stereotaxic injection of 5,7-DHT (Sigma-Aldrich) into the DRN. Four-month-old C57BL/6J male mice were injected with desipramine (Sigma-Aldrich; $25 \mathrm{mg} / \mathrm{mL}$ i.p.) 20 minutes before being placed in the stereotaxic frame in order to protect noradrenergic neurons. 5,7-DHT was dissolved in a $0.2 \%$ ascorbic acid solution to a final concentration of $0.5 \mu \mathrm{g} / \mathrm{mL}$, and $1 \mu \mathrm{L}$ was infused into the DRN (anteroposterior [AP], $4.5 \mathrm{~mm}$; mediolateral [ML], $0 \mathrm{~mm}$; dorsoventral [DV], 3,0 mm) over a period of 5 minutes. Control animals received $1 \mu \mathrm{L}$ of $0.2 \%$ ascorbic acid solution. Animals were culled 2 weeks after 5,7-DHT injection, and ChP from both LV and 4thV were collected from qPCR analysis. Alternatively, animals were transcardiacally perfused with PBS followed by $10 \%$ formalin, brains were removed and postfixed in $10 \%$ formalin for 4 hours, and paraffin-embedded and sectioned for serotonin immunostaining in the midbrain.

Statistics. All statistical analyses and graph designs were performed using GraphPad Prism (GraphPad Software). Unpaired 2-tailed Student's $t$ test, and 1-way ANOVA with Tukey's post hoc statistical tests were used to calculate $P$ values as detailed for each experiment, and statistical significance was accepted when $P$ values were lower than $0.05\left({ }^{*} P<0.05 ;{ }^{* *} P<0.01 ;{ }^{* * *} P<0.001\right)$. All the values are expressed as mean \pm SEM.

Study approval. All animal work was approved by the Animal Care and Use Committee of the National Institute on Aging Intramural Program (NIA-IRP, Baltimore, Maryland, USA), and all animals were housed at the NIA animal facility, which is fully accredited by the American Association for Accreditation of Laboratory Animal Care (AAALAC).

Table 4. Primary antibodies used for Western blotting

\begin{tabular}{|c|c|c|c|c|}
\hline Target & Manufacturer & Host & Catalog & RRID \\
\hline Syntaxin-1a & Cell Signaling Technology & Rabbit & 18572 & AB_2798803 \\
\hline VAMP2 & Cell Signaling Technology & Rabbit & 13508 & AB_2798240 \\
\hline VAMP3 & Cell Signaling Technology & Rabbit & 61451 & AB_2799609 \\
\hline NSF & Cell Signaling Technology & Rabbit & 3924 & AB_2155693 \\
\hline SNAP25 & Cell Signaling Technology & Rabbit & 5309 & AB_10624866 \\
\hline Synaptotagmin-1 & Cell Signaling Technology & Rabbit & 14558 & AB_2798510 \\
\hline Klotho & R\&D Systems & Goat & AF1819 & AB_2296612 \\
\hline$\beta$-Actin & Cell Signaling Technology & Mouse & 3700 & AB_2242334 \\
\hline
\end{tabular}




\section{Author contributions}

$\mathrm{CHM}$ conceived and designed the experiments, collected and interpreted the data, performed the analysis, and wrote the first draft of the manuscript. QRL helped to design the experiments and helped in the writing of the manuscript. DL helped in the collection of data. NH helped in the collection of data. JFO helped to design the experiments and helped in the collection of data. SC conceived and designed experiments, helped to interpret the data, and helped in the writing of the manuscript. JME conceived and designed the experiments, interpreted data, finalized the manuscript, and is the guarantor of the work.

\section{Acknowledgments}

This work was wholly supported by the Intramural Research Program of the National Institute on Aging/ NIH. We thank our scientific director, Luigi Ferrucci, and our director, Richard Hodes, for their unfailing support. We thank James Trevaskis and Gilead Sciences for cordially giving us IAPP antibody (FO2527.04) originally developed by Amylin Pharmaceuticals, and we thank Emily M. Murphy for all the help with the immunohistochemistry staining.

Address correspondence to: National Institute on Aging, Intramural Research Program, 251 Bayview Boulevard, Baltimore, Maryland 21224, USA. Phone: 410.558.8414; Email: eganj@mail.nih.gov.

1. Yoshitake T, et al. Incidence and risk factors of vascular dementia and Alzheimer's disease in a defined elderly Japanese population: the Hisayama Study. Neurology. 1995;45(6):1161-1168.

2. Ott A, Stolk RP, van Harskamp F, Pols HA, Hofman A, Breteler MM. Diabetes mellitus and the risk of dementia: The Rotterdam Study. Neurology. 1999;53(9):1937-1942.

3. Kuusisto J, et al. Association between features of the insulin resistance syndrome and Alzheimer's disease independently of apolipoprotein E4 phenotype: cross sectional population based study. BMJ. 1997;315(7115):1045-1049.

4. Luchsinger JA, Tang MX, Stern Y, Shea S, Mayeux R. Diabetes mellitus and risk of Alzheimer's disease and dementia with stroke in a multiethnic cohort. Am J Epidemiol. 2001;154(7):635-641.

5. Thambisetty M, et al. Glucose intolerance, insulin resistance, and pathological features of Alzheimer disease in the Baltimore Longitudinal Study of Aging. JAMA Neurol. 2013;70(9):1167-1172.

6. Killick R, et al. Deletion of Irs2 reduces amyloid deposition and rescues behavioural deficits in APP transgenic mice. Biochem Biophys Res Commun. 2009;386(1):257-262.

7. Freude S, et al. Neuronal IGF-1 resistance reduces Abeta accumulation and protects against premature death in a model of Alzheimer's disease. FASEB J. 2009;23(10):3315-3324.

8. Morris JZ, Tissenbaum HA, Ruvkun G. A phosphatidylinositol-3-OH kinase family member regulating longevity and diapause in Caenorhabditis elegans. Nature. 1996;382(6591):536-539.

9. Tissenbaum HA, Ruvkun G. An insulin-like signaling pathway affects both longevity and reproduction in Caenorhabditis elegans. Genetics. 1998;148(2):703-717.

10. Aigaki T, Seong KH, Matsuo T. Longevity determination genes in Drosophila melanogaster. Mech Ageing Dev. 2002;123(12):1531-1541.

11. Bartke A. Impact of reduced insulin-like growth factor-1/insulin signaling on aging in mammals: novel findings. Aging Cell. 2008;7(3):285-290.

12. Butler RN, et al. Longevity genes: from primitive organisms to humans. J Gerontol A Biol Sci Med Sci. 2003;58(7):581-584.

13. White MF. IRS2 integrates insulin/IGF1 signalling with metabolism, neurodegeneration and longevity. Diabetes Obes Metab. 2014;16 Suppl 1:4-15.

14. Avgerinos KI, Kalaitzidis G, Malli A, Kalaitzoglou D, Myserlis PG, Lioutas VA. Intranasal insulin in Alzheimer's dementia or mild cognitive impairment: a systematic review. J Neurol. 2018;265(7):1497-1510.

15. Rhea EM, Banks WA. Role of the Blood-Brain Barrier in Central Nervous System Insulin Resistance. Front Neurosci. 2019;13:521.

16. Gray SM, Aylor KW, Barrett EJ. Unravelling the regulation of insulin transport across the brain endothelial cell. Diabetologia. 2017;60(8):1512-1521

17. Leinwand SG, Chalasani SH. Neuropeptide signaling remodels chemosensory circuit composition in Caenorhabditis elegans. Nat Neurosci. 2013;16(10):1461-1467.

18. Luo J, Becnel J, Nichols CD, Nässel DR. Insulin-producing cells in the brain of adult Drosophila are regulated by the serotonin 5-HT1A receptor. Cell Mol Life Sci. 2012;69(3):471-484.

19. McRory JE, Sherwood NM. Ancient divergence of insulin and insulin-like growth factor. DNA Cell Biol. 1997;16(8):939-949.

20. Caruso MA, Sheridan MA. New insights into the signaling system and function of insulin in fish. Gen Comp Endocrinol. 2011;173(2):227-247

21. Doyle ME, et al. Insulin Is Transcribed and Translated in Mammalian Taste Bud Cells. Endocrinology. 2018;159(9):3331-3339.

22. Martin B, et al. Modulation of taste sensitivity by GLP-1 signaling in taste buds. Ann N Y Acad Sci. 2009;1170:98-101.

23. Lacroix MC, et al. Expression of insulin system in the olfactory epithelium: first approaches to its role and regulation. $J N e u r o-$ endocrinol. 2008;20(10):1176-1190.

24. Havrankova J, Schmechel D, Roth J, Brownstein M. Identification of insulin in rat brain. Proc Natl Acad Sci USA. 1978;75(11):5737-5741. 
25. Havrankova J, Roth J, Brownstein MJ. Concentrations of insulin and insulin receptors in the brain are independent of peripheral insulin levels. Studies of obese and streptozotocin-treated rodents. J Clin Invest. 1979;64(2):636-642.

26. Deltour L, et al. Differential expression of the two nonallelic proinsulin genes in the developing mouse embryo. Proc Natl Acad Sci USA. 1993;90(2):527-531.

27. Devaskar SU, Singh BS, Carnaghi LR, Rajakumar PA, Giddings SJ. Insulin II gene expression in rat central nervous system. Regul Pept. 1993;48(1-2):55-63.

28. de la Monte SM, Wands JR. Review of insulin and insulin-like growth factor expression, signaling, and malfunction in the central nervous system: relevance to Alzheimer's disease. J Alzheimers Dis. 2005;7(1):45-61.

29. Clarke DW, Mudd L, Boyd FT, Fields M, Raizada MK. Insulin is released from rat brain neuronal cells in culture. J Neurochem. 1986;47(3):831-836

30. Kuwabara T, et al. Insulin biosynthesis in neuronal progenitors derived from adult hippocampus and the olfactory bulb. $E M B O$ Mol Med. 2011;3(12):742-754.

31. Mehran AE, et al. Hyperinsulinemia drives diet-induced obesity independently of brain insulin production. Cell Metab. 2012;16(6):723-737

32. Takano K, et al. Insulin expression in cultured astrocytes and the decrease by amyloid $\beta$. Neurochem Int. 2018;119:171-177.

33. Orci L, et al. Conversion of proinsulin to insulin occurs coordinately with acidification of maturing secretory vesicles. $J$ Cell Biol. 1986;103(6 Pt 1):2273-2281.

34. O'Leary NA, et al. Reference sequence (RefSeq) database at NCBI: current status, taxonomic expansion, and functional annotation. Nucleic Acids Res. 2016;44(D1):D733-D745.

35. Xiong QY, Yu C, Zhang Y, Ling L, Wang L, Gao JL. Key proteins involved in insulin vesicle exocytosis and secretion. Biomed Rep. 2017;6(2):134-139.

36. Conn PJ, Sanders-Bush E, Hoffman BJ, Hartig PR. A unique serotonin receptor in choroid plexus is linked to phosphatidylinositol turnover. Proc Natl Acad Sci USA. 1986;83(11):4086-4088.

37. Dani N, et al. A cellular and spatial map of the choroid plexus across brain ventricles and ages. BioRxiv. https://doi. org/10.1101/627539. Published May 5, 2019. Accessed November 18, 2019

38. Lamotte L, Jackerott M, Bucchini D, Jami J, Joshi RL, Deltour L. Knock-in of diphteria toxin A chain gene at Ins2 locus: effects on islet development and localization of Ins2 expression in the brain. Transgenic Res. 2004;13(5):463-473

39. Li L, et al. Knockin of Cre Gene at Ins2 Locus Reveals No Cre Activity in Mouse Hypothalamic Neurons. Sci Rep. 2016;6:20438.

40. Rother E, et al. Acute selective ablation of rat insulin promoter-expressing (RIPHER) neurons defines their orexigenic nature. Proc Natl Acad Sci USA. 2012;109(44):18132-18137.

41. Wang B, et al. Activation of hypothalamic RIP-Cre neurons promotes beiging of WAT via sympathetic nervous system. $E M B O$ Rep. 2018;19(4):e44977.

42. Ray MK, Fagan SP, Moldovan S, DeMayo FJ, Brunicardi FC. Development of a transgenic mouse model using rat insulin promoter to drive the expression of CRE recombinase in a tissue-specific manner. Int J Pancreatol. 1999;25(3):157-163.

43. Millar ID, Bruce JIe, Brown PD. Ion channel diversity, channel expression and function in the choroid plexuses. Cerebrospinal Fluid Res. 2007;4:8.

44. Lukinius A, Wilander E, Westermark GT, Engström U, Westermark P. Co-localization of islet amyloid polypeptide and insulin in the B cell secretory granules of the human pancreatic islets. Diabetologia. 1989;32(4):240-244.

45. Banks WA, Kastin AJ, Maness LM, Huang W, Jaspan JB. Permeability of the blood-brain barrier to amylin. Life Sci. 1995;57(22):1993-2001

46. Beaumont K, Kenney MA, Young AA, Rink TJ. High affinity amylin binding sites in rat brain. Mol Pharmacol. 1993;44(3):493-497.

47. Li Z, Kelly L, Heiman M, Greengard P, Friedman JM. Hypothalamic Amylin Acts in Concert with Leptin to Regulate Food Intake. Cell Metab. 2015;22(6):1059-1067

48. Hartig PR, Evans MJ, Krohn AM, Leder SA, Sze PC, Stoffers DA. [(125)I]LSD binding to serotonin and dopamine receptors in bovine caudate membranes. Neurochem Int. 1985;7(4):699-707.

49. Lindvall-Axelsson M, Mathew C, Nilsson C, Owman C. Effect of 5-hydroxytryptamine on the rate of cerebrospinal fluid production in rabbit. Exp Neurol. 1988;99(2):362-368.

50. Faraci FM, Mayhan WG, Heistad DD. Effect of serotonin on blood flow to the choroid plexus. Brain Res. 1989;478(1):121-126.

51. Nakamura S, Sasaki J, Tsubokawa T. Serotonergic effects on carbonic anhydrase activity in the choroid plexus. Childs Nerv Syst. 1991;7(8):442-447.

52. Fisone G, Snyder GL, Aperia A, Greengard P. Na+,K(+)-ATPase phosphorylation in the choroid plexus: synergistic regulation by serotonin/protein kinase C and isoproterenol/cAMP-PK/PP-1 pathways. Mol Med. 1998;4(4):258-265.

53. Lindvall M, Owman C. Autonomic nerves in the mammalian choroid plexus and their influence on the formation of cerebrospinal fluid. J Cereb Blood Flow Metab. 1981;1(3):245-266.

54. Napoleone P, Sancesario G, Amenta F. Indoleaminergic innervation of rat choroid plexus: a fluorescence histochemical study Neurosci Lett. 1982;34(2):143-147.

55. Moskowitz MA, Liebmann JE, Reinhard JF, Schlosberg A. Raphe origin of serotonin-containing neurons within choroid plexus of the rat. Brain Res. 1979;169(3):590-594.

56. Brightman MW, Palay SL. The fine structure of ependyma in the brain of the rat. J Cell Biol. 1963;19:415-439.

57. Chan-Palay V. Serotonin axons in the supra- and subependymal plexuses and in the leptomeninges; their roles in local alterations of cerebrospinal fluid and vasomotor activity. Brain Res. 1976;102(1):103-130.

58. Aghajanian GK, Gallager DW. Raphe origin of serotonergic nerves terminating in the cerebral ventricles. Brain Res. $1975 ; 88(2): 221-231$.

59. Ohara-Imaizumi M, et al. Serotonin regulates glucose-stimulated insulin secretion from pancreatic $\beta$ cells during pregnancy. Proc Natl Acad Sci USA. 2013;110(48):19420-19425.

60. Kim H, et al. Serotonin regulates pancreatic beta cell mass during pregnancy. Nat Med. 2010;16(7):804-808

61. Orosco M, Gerozissis K, Rouch C, Nicolaïdis S. Feeding-related immunoreactive insulin changes in the PVN-VMH revealed by 
microdialysis. Brain Res. 1995;671(1):149-158.

62. Rouch C, Nicolaidis S, Orosco M. Determination, using microdialysis, of hypothalamic serotonin variations in response to different macronutrients. Physiol Behav. 1999;65(4-5):653-657.

63. Orosco M, Rouch C, Gerozissis K. Activation of hypothalamic insulin by serotonin is the primary event of the insulin-serotonin interaction involved in the control of feeding. Brain Res. 2000;872(1-2):64-70.

64. Kolta MG, Soliman KF, Williams BB. Role of 5-hydroxytryptamine in the regulation of brain neuropeptides in normal and diabetic rat. Horm Res. 1986;23(2):112-121.

65. Davidson DA, et al. Evidence for separate receptors for insulin and insulin-like growth factor-I in choroid plexus of rat brain by quantitative autoradiography. J Histochem Cytochem. 1990;38(9):1289-1294.

66. Fuster DG, Bobulescu IA, Zhang J, Wade J, Moe OW. Characterization of the regulation of renal Na+/H+ exchanger NHE3 by insulin. Am J Physiol Renal Physiol. 2007;292(2):F577-F585.

67. Kahn AM, Yang M. Insulin increases acid production and may directly stimulate $\mathrm{Na} / \mathrm{H}(+)$ exchange activity in cultured vascular smooth muscle cells. J Vasc Res. 2011;48(6):505-512

68. Johanson CE, Murphy VA. Acetazolamide and insulin alter choroid plexus epithelial cell [Na+], pH, and volume. Am JPhysiol. 1990;258(6 Pt 2):F1538-F1546.

69. Hurley JH, et al. Insulin signaling inhibits the 5-HT2C receptor in choroid plexus via MAP kinase. BMC Neurosci. $2003 ; 4: 10$.

70. Rhea EM, Rask-Madsen C, Banks WA. Insulin transport across the blood-brain barrier can occur independently of the insulin receptor. J Physiol (Lond). 2018;596(19):4753-4765.

71. Konishi M, et al. Endothelial insulin receptors differentially control insulin signaling kinetics in peripheral tissues and brain of mice. Proc Natl Acad Sci USA. 2017;114(40):E8478-E8487.

72. Johnson BA, et al. Accurate, strong, and stable reporting of choroid plexus epithelial cells in transgenic mice using a human transthyretin BAC. Fluids Barriers CNS. 2018;15(1):22

73. Spector R. Pharmacokinetics and metabolism of cytosine arabinoside in the central nervous system. J Pharmacol Exp Ther. 1982;222(1):1-6.

74. Liu QR, et al. Identification of novel mouse and rat CB1R isoforms and in silico modeling of human CB1R for peripheral cannabinoid therapeutics. Acta Pharmacol Sin. 2019;40(3):387-397. 